\title{
New high fill-factor triangular microlens array fabrication method using UV proximity printing
}

\author{
Tsung-Hung Lin · Hsiharng Yang •
}

Ching-Kong Chao · Shih-Yu Hung

Published online: 30 May 2009

(C) Springer-Verlag 2009

Erratum to: Microsyst Technol

DOI 10.1007/s00542-008-0728-7

Unfortunately, an error occurred in Fig. 2a in the original version. The correct figure is shown below.

The online version of the original article can be found under doi:10.1007/s00542-008-0728-7.

T.-H. Lin · C.-K. Chao

Department of Mechanical Engineering, National Taiwan

University of Science and Technology, Taipei 105, Taiwan

H. Yang $(\bowtie)$

Institute of Precision Engineering, National Chung Hsing

University, Taichung 402, Taiwan

e-mail: hsiharng@nchu.edu.tw

S.-Y. Hung

Department of Automation Engineering,

Nan Kai Institute of Technology, Nantou 542, Taiwan 
A

\section{$\mathrm{W} / \mathrm{m}^{2}$}

\begin{tabular}{l}
\hline $80000-$ \\
75000 \\
70000 \\
65000 \\
60000 \\
55000 \\
$50000-$ \\
45000 \\
40000 \\
35000 \\
$30000-$ \\
$25000-$ \\
\hline $20000-$ \\
15000 \\
\hline $10000-$ \\
$5000-$ \\
\hline 0
\end{tabular}

Total - Irradiance Map for Absorbed Flux Block 1 Surface 4

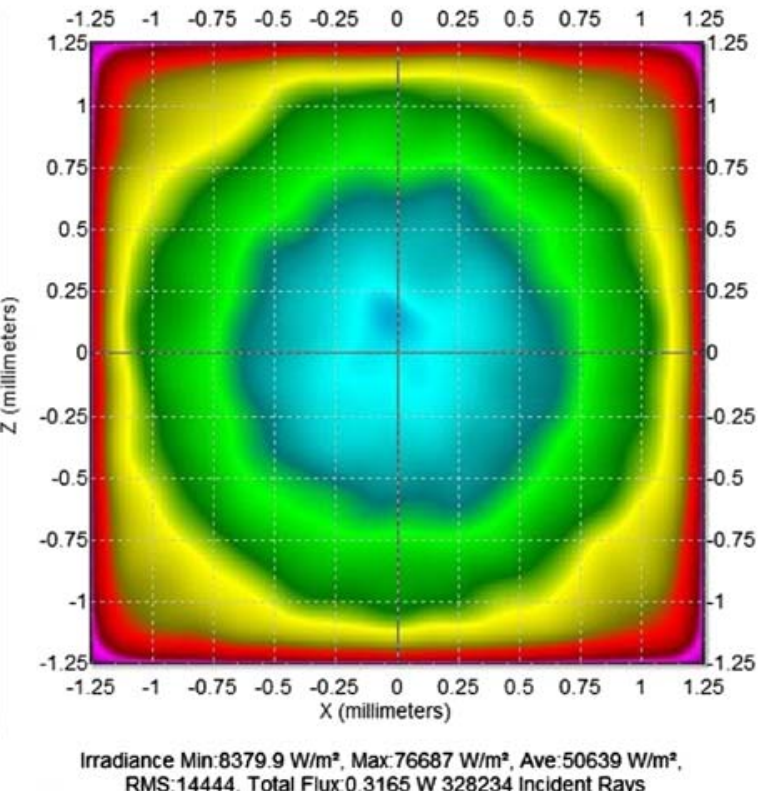
RMS:14444. Total Flux 0.3165 W 328234 Incident Rays

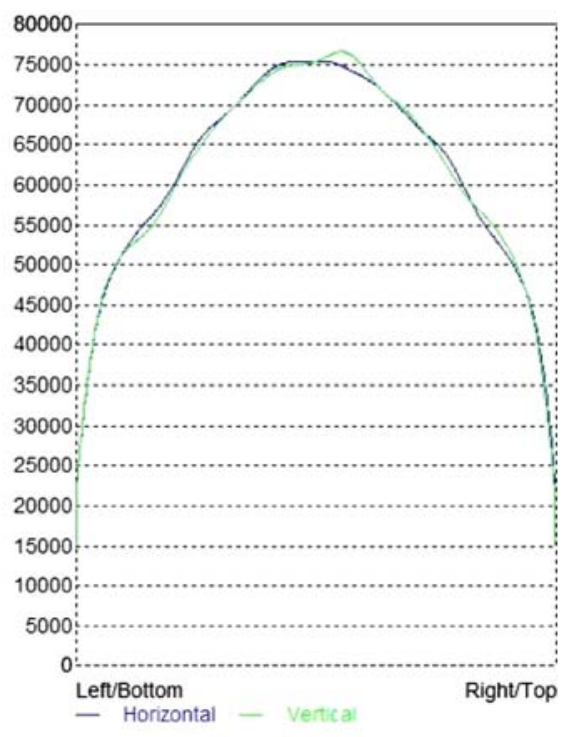

Fig. 2a 